ИНФОРМАЦИОННОЕ ПРОСТРАНСТВО. МЕДИАСРЕДА INFORMATION SPACE. MEDIA ENVIRONMENT

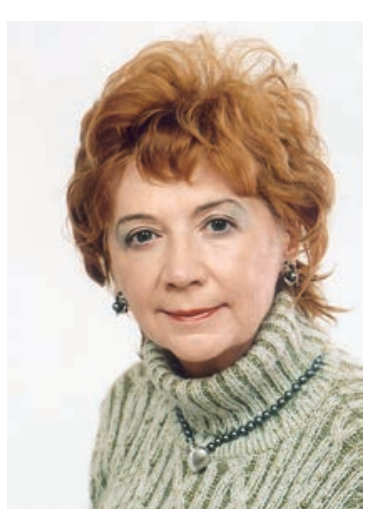

\section{Сусская Ольга Александровна}

Кандидат филологических наук, доцент

Кафедра связей с общественностью, факультет социальных наук и социальных технологий, Национальный университет «Киево-Могилянская Академия», 04070, Украина, г. Киев, ул. Сковороды Григория, 2, e-mail: susskaya@bigmir.net

\section{Olga A. Susskaya}

$\mathrm{PhD}$ in Philology, Assistant Professor

Department of Public Relations, Faculty of Social Science and Social Technologies, National University "Kievo-Mohylianskaya Academy”, 2 Skovorody Grigoriya Str., Kiev, 04070, Ukraine, e-mail: susskaya@bigmir.net

\title{
РАЦИОГУМАНИСТИЧЕСКИЕ ТЕНДЕНЦИИ В ИЗУЧЕНИИ ИНФОРМАЦИОННОГО ПРОСТРАНСТВА
}

\begin{abstract}
Аннотация. В статье рассматриваются актуальные для теории массовой коммуникации и социологических исследований общественного сознания наметившиеся тенденции интердисциплинарного переноса рациогуманистического подхода (ранее присутствовавшего в основном в психологии) в проблематику изучения информационного пространства социологией массовых коммуникаций, медиапсихологией и журналистикой. Специфика медиасистемы раскрывается на примерах ее взаимодействия с политической системой общества. Акцентируется недостаточный интерес к изучению проблем гуманизации информационного пространства, хотя именно путь избрания гуманитарной, а не манипулятивной стратегии в сфрере массовой коммуникации может нейтрализовать ряд существенных проблем как внутри медиасистем, так и вокруг современных СМИ. Современные принципы рациогуманизма впервые применяются к познанию сферы медиакоммуникаций, что позволяет, основываясь на их репродуктивно-нормативной и диалогично-творческой функциях, методологически разрабатывать идеи взаимодополняемости глобального медиапространства и индивидуального информационного поля субъекта медиакоммуникаций. Особо рассматривается принцип ориентированности на культуру, анализируются возможности интеркультурных взаимодействий в направлении «гуманистического глобализма». Выявленные тенденции рациогуманистического подхода открывают перспективы гуманизации механизмов формирования массового сознания в условиях кризисного общества.
\end{abstract}

Ключевые слова. Массовая коммуникация, медиасистема, рациогуманизм, информационное пространство, теория коммуникаций, масс-медиа.

Информация о статье. Дата поступления 16 фревраля 2018 г.; дата принятия к печати 06 апреля 2018 г;; дата онлайн-размещения 20 апреля 2018 г. 


\title{
RATIO-HUMANIST TRENDS IN STUDYING INFORMATION SPACE
}

\begin{abstract}
The article discusses new tendencies of interdisciplinary transfer of ratio-humanist approach (which was earlier applied in psychology) to the issues of studying information space by sociology of mass communications, media psychology and journalism. These new tendencies are important for theory of mass communications and sociological studies of public opinion. The specifics of the media system are revealed through the media system's interaction with the political system of society. The author emphasizes that there is little interest in studying the problems of humanizing information space, though choosing a humanitarian vs. manipulative strategy in mass communications can neutralize some significant problems within media systems as well as the problems related to the modern mass media. Modern principles of ratio-humanism are applied, for the first time, to learning media communications, which makes it possible to methodologically develop ideas of complementarity of the global media space and the individual information field of the subject of media communications, based on the above principles' reproductive-normative and dialogic-creative functions. Special attention is paid to the principle of culture orientation, the possibilities of intercultural interactions aimed at "humanistic globalism" are analyzed. The revealed tendencies of the ratio-humanist approach open up prospects for humanization of mechanisms of shaping collective consciousness in a crisis society.
\end{abstract}

Keywords. Mass communication, media system, ratio-humanism, information space, communication theory, mass media.

Article info. Received February 16, 2018; accepted April 06, 2018; available online April 20, 2018.

Постановка проблемы распространения рациогуманистических тенденций в изучении информационного пространства не только в ракурсе психологического видения, но и в более широком спектре интересов социогуманитарных наук соответствует современным направлениям интердисциплинарных подходов.

В рамках мультикультурологических или лингвосоциопсихологических (Т. М. Дридзе [1]) теоретикометодологических позиций информационное пространство не может отождествляться с системой СМИ какой-либо конкретной страны, ибо а) представляет собой перцептуально и когнитивно воспринятое содер- жание сообщений, которое выступает в этом случае как сочетание функций массового сознания, и б) может быть определено только в опосредованном варианте, например с помощью социологических (изучение общественного мнения социологией массовых коммуникаций), социопсихологических и психолингвистических, журналистских, собственно фрилологических исследований (включая семиотические).

Приоритетность социологических исследований информационного пространства в определении вопросов социального порядка и психолингвистических исследований дискурса масс-медиа - в вопросах его гуманизации (в ракурсе видения это- 
го вопроса фрилологической наукой и гуманистической психологией) фокусируется сегодня на актуальном владении «совокупным коммуникатором» (выступающим как олицетворение институциональной стороны), необходимыми знаниями о реальном состоянии информационного пространства. Недостаток информации является причиной накопления ряда нерешенных проблем в ситуации с проведением качественно-количественных исследований в этой области, а также в информационной политике, особенно тех стран, внутри которых происходят кризисные явления (например, в Украине).

Анализ аспектов осознания аудиторией электронных медиа и сети Интернет как «актуальности социального бытия», в том числе идеи взаимодополняемости глобального медиапространства и индивидуального информационного поля субъекта медиакоммуникаций, благодаря компьютерным технологиям ставшего более независимым, представляет отдельное направление в современных медиакоммуникативных теориях и журналистике [2; 3]. Особое место занимает социологическое изучение проблем репрезентации сочетания возможностей создания собственного содержания в информационном поле субъекта и отражения этих идей (с учетом вхождения в глобальные сети) в массовом сознании. Один из основателей рациогуманистической ориентации в советской и впоследствии украинской психологии Г. А. Балл подчеркивал, что в научном познании не обойтись простыми моделями, однако их усложнение должно мотивироваться не стремлением к «внешней солидности», наукообразию, а содержа- тельно - необходимостью учета факторов, «от которых более простые модели абстрагировались» [4]. Так, чтобы учесть особенности внутренне сложных жизненных миров, необходимо учитывать и так называемый модус культуры (Г. А. Балл, В. А. Мединцев [5]), воплощенный в репродуктивно-нормативной и диалогично-творческой функции. Известные позиции и направления изучения культуры (ведь содержание информационного пространства так или иначе представляет собой объект культуры), заложенные М. С. Каганом, В. С. Библером, М. М. Бахтиным, А.Я. Флиером и др., реализовывались в рамках аксиологического и онтогносеологического подходов. Однако уже их последователи А. П. Давыдов, Д. А. Леонтьев, В. М. Межуев, К. Э. Разлогов, В. С. Степин показывают сопряжение этих подходов с рациогуманистическими идеями диалогичности и творчества. К. Э. Разлогов отмечает, что «именно культура в широком антропологическом понимании этого термина позволяет свести вместе разные стороны человеческой деятельности, направленные на развитие самого человека и человеческих общностей» [6, с. 150].

Очевидно, рамки глобального медиапространства (гипертрофированного реального) расширились до необъятных пределов, человек попал в мир «гиперреальности», как писал Жан Бодрийяр в своей известной книге «Симулякры и симуляция»: «Сегодня реальное стало алиби модели в мире, которым руководит принцип симуляции. Парадоксально, именно реальное стало нашей настоящей утопией» [7, с. 177]. Возможно, только научная франта- 
стика эпохи кибернетического прорыва может позволить себе «реально» отражать этот созданный собственноручно мир гиперреальности. Ведь большинство фантомов этого виртуального мира создано именно людьми индустриального этапа развития общества, и доминирование традиционных или классических технологий масс-медиа также присуще именно этому периоду.

В условиях нестабильности и десормирования социальной реальности меняется и система ценностей; возрастает личностная неуверенность и дезинтеграция, меняется наполненность и структура ценностных ориентаций, которые составляют важное основание для саморазвития личности. Появляются новые ценностные ориентиры (чаще всего весьма далекие от рациогуманистического толка), и благодаря контактам с информационным пространством эти, как точно сформулировал А. А. Бодалев, «усвоенные ценности становятся элементами системы ценностных ориентаций личности, важным компонентом самосознания» $[8$, с. 84].

Действительно, традиционные элементы оценки эффективности работы СМИ сегодня уже не отражают вполне реальной ситуации, ведь реципиенты (с социально-психологической точки зрения восприятие смыслов совершается именно реципиентами) представляют собой уже не тот «медиаландшафт» с его социогрупповой структурой; а глобальное информационное пространство (global sphere) и содержание, присутствующее в нем, уже не находятся в поле действия какойлибо одной, отдельно взятой системы СМИ.
В измерениях и понимании социологии массовых коммуникаций система традиционных СМИ, работающих на данной территории, их действия детерминированы условиями и правом выбора аудитории (последнее может оказаться только правом, если это касается территорий, где имеется неуверенный прием трансляции каналов традиционных массмедиа). Однако выбор в интернетсетях происходит все более активно в соответствии с предпочтениями, оценками, интересами, личностными «культурными проекциями» и ценностными ориентациями аудиторий СМИ [9], чем, к сожалению, современные исследователи интересуются все меньше.

Проблематичным выглядит также и наличествующее расхождение в понимании существования так называемой общественно-политической типологии СМИ и их коммуникативной типологии. С точки зрения рациогуманистической перспективы рассмотрения этих типологий существующая в Украине система СМИ могла бы быть коммуникативной, но в условиях кризиса так или иначе используемая в политических целях данная система СМИ больше обслуживает социально-политические задачи, нежели общегуманизационные, культурно-просветительские и собственно коммуникативные. Очевидно, сегодня наличествует противоположность между «информационным меню» и «информационным выбором» аудитории.

Информационный выбор всегда был неотъемлемым правом самой аудитории СМИ, воплощением субъектных предпочтений, интересов, информационных потребностей его «акторов» - участников коммуни- 
кационного процесса (Ю. Хабермас) [10]. Лишить их этого права, как и общего права на информацию, в условиях глобализированного медиакоммуникативного пространства невозможно, тем более что это право закреплено законодательством (на уровне ООН и конкретных стран). Мнимая, искусственная очерченность «границ» информационного пространства может стать большим недостатком, барьером на пути развития национальных систем СМИ. Так, в начале 90-х, практически не имея выхода в информационное пространство стран дальнего зарубежья (кроме спутникового телевидения, тогда - в период экономического кризиса - доступного лишь немногим, а также коротковолнового радиовещания и в некоторой степени с возможностью приема передач средневолнового диапазона), традиционные медиа Украины вынужденно оказались в положении так называемой замкнутой информационной среды, имеющей следующие характерные черты:

- определенность количественHыX параметров аудитории (с тенденцией к снижению), которая полностью зависит от технических условий покрытия территории сигналом тех или иных каналов ТВ и радиовещания, доступа в Интернет и т. п;

- ограниченность информации региональными рамками (информация из стран дальнего и ближнего зарубежья поступает по отдельным каналам, в том числе техническим, из самого зарубежья);

- низкоэквивалентность некоторых национальных украинских каналов ТВ и радиовещания по сравнению с национальными каналами развитых стран Европы и Америки.
К толкованию понятий низкоэквивалентных и высокоэквивалентных каналов традиционных медиа:

- надо принять во внимание, что в собственности государственных каналов остаются сконцентрированными основные фонды и технические мощности, а это значит, что они автоматически сохраняют самые большие масштабы охвата (покрытия территорий) и потенциал максимального объема аудитории;

- в зависимости от масштабов вещания и покрытия максимального объема аудитории на территориях, куда достигают технические возможности этих каналов, государственные каналы телевидения еще долго могли бы сохранять свою потенциально высокую эквивалентность, однако для этого им необходимо сохранить высокопрофессиональный кадровый состав и производить собственные высококачественные в творческом отношении программы.

Однако когда в окружающей среде происходят непредсказуемые негативные события (иногда угрожающие жизни), когда в масс-медийном пространстве информация доносится искаженно, когда «негативные стереотипы могут не только касаться используемых в научной деятельности средств, но и проявляться в установках, прежде всего конфронтационных» [11, с. 80-82], интерпретационные возможности реципиента СМИ сужаются / расширяются не только в зависимости от его принадлежности к возрастной группе или его психического состояния, но и параллельно с возможностями получения им «информации о мире, который нас окружает». Что справедливо и с точки зрения рассмотрения современного состояния 
масс-медийного дискурса, и с точки зрения общей ситуации в информационном пространстве Украины.

Учитывая, что общественное мнение телерадиоаудитории является одним из концептов - составляющих индивидуального и общественного сознания, справедливо будет считать одной из рациогуманистических тенденций в области теле- и радиожурналистики продвижение демократических начал и самой философии общественного вещания, максимально независимого от властных структур.

В этом русле должно было происходить и состоявшееся в 2017 году переформатирование национальной сети телерадиовещания Украины в общественное вещание с последующей ликвидацией самостоятельных региональных вещателей (областные и другие местные телерадиокомпании превращаются в сокращенные количественно филиалы), что, однако, привело к падению вещательного потенциала и объемов аудиторий, в частности ведущего национального канала «UA: Первый» и др.

В нынешних условиях, когда «UA: Первый» канал украинского телевидения явно уступает другим телеканалам, в частности «1+1», «Интер», «Украина» и др. и в объемах аудитории, и в качестве телепередач, рождаются кабельные и онлайновые самостоятельные центры и телекомпании. Именно к этим компаниям уже сегодня наблюдается отток наиболее творчески одаренных журналистов и профессионально грамотных телеспециалистов (в частности, специалистов по ИТ-технологиям); следовательно, и конкурентоспособность, и профессиональная высоко- эквивалентность этих каналов будет со временем значительно выше, чем каналов «общественного» государственного телевидения.

В связи с вышеуказанными профессионально-технологическими и менеджерскими проблемами средний уровень профессионализма персонала государственных компаний будет постепенно снижаться и дальше. Достаточно заметно ослабляется выработанная на предыдущих этапах «внутренняя фрилософия» становления общественного вещания, его существования и развития как наиболее объективного (по качеству информации) канала, благодаря которому миллионы людей имели бы возможность ознакомиться с реальными фактами в области социальной жизни, политиками, их деятельностью и т. п.

Именно благодаря средствам массового информирования (как видим, по коммуникации, которая предусматривает двусторонность информационного обмена) была наработана установка на авторитет государственных каналов радио и телевидения и доверие к ним: этот «запас прочности» украинское национальное и/или региональное телерадиовещание использовали практически в течение всего первого десятилетия XXI века. Подобный кредит доверия к традиционным медиа как значимой силе в обществе характерен для многих стран, но это доверие легко поколебать и свести на нет. Так, в течение следующих восьми лет это доверие существенно упало. Здесь можно провести параллель с известным в политической социологии индексом «эффективного» числа партий, формулу расчета которого в 1979 году впервые разра- 
ботали Микку Лааксо и Рейн Таагепера [12; 13]. Его успешно применяет украинский социолог А.И. Вишняк, который акцентирует, что «этот индекс является средством измерения для разных стран и разных периодов количества партий, которые оказывают влияние на политический процесс» $[14$, с. 172].

Если сейчас (по данным социологических исследований аудитории традиционных медиа) мы можем констатировать, что потенциальное покрытие аудитории в Украине осуществляется на уровне 60 \% (в среднем), то для государственных каналов этот показатель выше на 20-30 \%, а значит, преимущественно только на этих традиционных каналах и происходит вся так называемая политическая борьба за место в парламенте. В таблице дана развернутая картина по годам электоральных кампаний в Украине по индексам ENPV и ENPS, демонстрирующая сделанные А. И. Вишняком [14, с. 173] расчеты по определению индекса «эффрективного» числа парламентских партий, совершенные на основании статистики парламентских выборов 1998-2014 гг.

К сожалению, подавляющее большинство информации, приме- ров, всего того, что используется для отработки направлений поведения и создания имиджа современных украинских политиков, часто берется из зарубежного опыта и не соответствует запросам украинской общественности и не может быть правильно воспроизведено в общественном мнении. В социуме, который находится на рубеже исторических эпох, в процессе трансформации - активного перехода от тоталитарного к демократическому, от централизованно-государственного управления экономическими процессами к их рыночному регулированию, от идейного единодушия и поддержки «генеральной» линии или «генерального» лидера к идейному плюрализму и созданию национальной лидерской элиты, в том числе политической, всегда происходят процессы переосмысления и переоценки многих ранее стереотипизированных позиций и истин, которые порождают определенный сдвиг ценностных ориентаций, отрабатываются новые социальные установки, ценностные ориентиры и стереотипы, которые впоследствии могут обрести значение социальных норм.

Снижение ответственности СМК за события и процессы, происходя-

Тенденции изменения «эффективного» числа политических партий в ходе парламентских выборов, \%

\begin{tabular}{|l|c|c|c|c|c|c|}
\hline \multicolumn{1}{|c|}{ Индексы* } & 1998 & 2002 & 2006 & 2007 & 2012 & 2014 \\
\hline $\begin{array}{l}\text { «Эфрфективное» число электо- } \\
\text { ральных партий (ENPV) }\end{array}$ & 10,7 & 7,9 & 5,6 & 4,2 & 5,0 & 7,5 \\
\hline $\begin{array}{l}\text { «Эфффективное» число парла- } \\
\text { ментских партий (ENPS) }\end{array}$ & 5,0 & 4,8 & 3,4 & 3,3 & 4,3 & 4,8 \\
\hline
\end{tabular}

* Расчеты по статистике результатов выборов, опубликованных на сайте ЦИк Украины (cvk.gov.ua). 
щие в обществе, для массового сознания вообще означает, что перестал существовать еще один инструмент реального управления нашим сложным кризисным обществом. Параллельно с этими процессами усиливается использование системы СМИ для разного типа манипуляций массовым сознанием. Особенно яркими примерами изобилует в этом смысле проведение электоральных кампаний, когда «машина манипуляций» приобретает исключительное воздействие и пытается «одолеть» рациогуманизм, присущий и массовому сознанию, и общественному мнению (хотя последнее и само нередко оказывается инструментом электоральных кампаний).

Подчеркнем, что в обществе, где большинство прав и свобод граждан не подкреплено экономически и организационно, где отсутствуют механизмы реализации правовых гарантий и постулатов, где эти права только декларируются и выполняют роль «заставки», цивилизационного «клише», которым прикрывается власть, якобы демократически выбранная и легитимная, - именно в таком обществе немаловажную роль начинает играть манипуляция информацией и возникает соблазн все более широкого применения разного рода манипуляций.

Параллельно растет и недоверие к содержанию и каналов СМИ, особенно к информации о сущности политической жизни, экономических, общественных отношений и ситуации в стране, что тесно коррелирует с низким уровнем доверия к властным структурам. По данным социологического центра «Демократические инициативы» им. И. Кучерива (опрос состоялся в декабре 2017 г.), среди политических институтов наиболее отрицательный баланс доверия имеют: Верховная Рада Украины (-76\%), государственный аппарат (-75\%), политические партии $(-71 \%)$, Правительство Украины $(-65 \%)$ и Президент Украины (-60 \%). В группе «лидеров недоверия» также оказались такие составляющие правоохранительной системы, как суды (-75 \%) и прокуратура (-74 \%). Очень высок уровень недоверия к финансовым структурам, в частности к коммерческим банкам $(-73 \%)$ и Национальному банку Украины (-67 \%). Наихудший баланс доверия / недоверия имеют российские СМИ (-77\%). Негативный баланс доверия / недоверия имеют и другие социальные институты: полиция $(-46 \%)$, СБУ $(-26,5 \%)$, профсоюзы (-25\%), западные СМИ $(-22 \%)$, патрульная полиция (-19\%), омбудсман (-17\% ), НАБУ (-12\%), органы местного самоуправления $(-12 \%)$, СМИ Украины $(-6 \%)^{1}$.

И именно в этой ситуации, как прямое следствие, наступает период, когда в информационной сфере предпочтение отдается так называемым манипулятивным стратегиям распространения (в том числе создания и воспроизведения) информации и в целом - формирования общественного мнения. Суть их заключается в том, что поток целенаправленной, иногда враждебной (относительно намерений искажения событий) информации производит воздействие на аудиторию. Для достижения манипулятивных целей используются различного вида клише,

${ }^{1}$ Результаты опроса // Фонд «Демократические инициативы» им. И. Кучерива. Декабрь 2017 г. URL : http://dif.org.ua/article/ reytingijfojseojoej8567547. 
стереотипы, представления; с помощью конкретных (чаще искаженных) ценностных установок меняются «ориентиры», с их помощью происходит включение людей в деятельность, содержание которой, цель и задачи ими рационально не осознаются. Так, украинский медиакритик и политолог В. В. Цыганов отмечает, что «создание нервозности, нагнетание угроз и страхов, “фобизация" общественной жизни с целью ввергнуть и удерживать население в состоянии непрерывного, перманентного стресса является определяющим принципом медиа-терроризма» [15, с. 56].

В современном мире создана практически идеальная система «мифообеспечения» политикума ею может выступать подчиненная власти система средств массовой коммуникации, которая, особенно в условиях даже частичной подчиненности властным (в том числе олигархическим) структурам и экономической зависимости от них, будет преимущественно воплощать мифологемы, необходимые правящим элитам.

В отличие от манипулятивной, гуманистическая стратегия, реализуемая через систему массовой коммуникации (которая осознается как более широкая по своим функциям, нежели «совокупный коммуникатор» СМИ), предусматривает, что объект формирования общественного мнения определенным социальным субъектом активно и избирательно воспринимает адресованные ему информацию, оценки, суждения, комментарии и т. п.; интерпретирует их содержание через призму своих потребностей, интересов, ценностных ориентаций, приоб- ретенного жизненного опыта, а это преимущественно совпадает в своих основных положениях с идеями рациогуманизма.

Рассматривая поведение масс с точки зрения единства экономики, политики и культуры, следует сразу подчеркнуть значимость фрактора культуры как наиболее основательного фундамента фрактического (а не мнимого) потенциала общества. По состоянию культуры можно выяснить, может ли это общество быстро прогрессировать, или его ожидает регресс или топтание на месте. Согласно В. С. Библеру, «цивилизация входит в самое ядро произведений культуры, в культурную жизнь как необходимое <...> технологическое изобретение и сопровождает жизнь культуры постоянно, накапливаясь и развиваясь» [16, с. 288].

Культура связана с общественным бытием более конкретно, ведь она воплощается в каждом поступке человека в реальных жизненных процессах, в реагировании на те или иные политические события, она не просто «обслуживает», а обеспечивает (или должна обеспечивать) духовно, морально, философски и т. д.

В системе принципов рациогуманизма среди важнейших представляется «принцип ориентированности на культуру» [17], органично сочетающийся с принципом «ориентированности на персону». В статье «Гуманитарные науки и будущее современной цивилизации» В. В.Иванов отмечает, что «сохранение индивидуального своеобразия каждой отдельной культуры и языка остается одной из важных задач всемирного гуманитарного сообщества» [18, с. 10]. Очевидно также, что глобалистический гуманизм или 
«гуманистический глобализм» в значительной степени отграничивает себя от наиболее распространенных технократически унифицированных моделей глобализации, обслуживающих сегодня эгоистичные интересы верхушки наиболее богатых стран, одновременно не поддерживает и «карнавально-хулиганские» практики так называемых антиглобалистов (к тому же, по всей вероятности, включенных в глобализированный медиабизнес). Очевидно, формальные социальные институты, структурирующие политику, преимущественно принадлежат к сфере «символического производства» или «производства смыслов» (П. Бурдье) [19]. Как выход, здесь возможно лишь следование принципу выявления позитивных (соответствующих гуманистическим ценностям) возможностей на основе диалого-гуманистического подхода как в социальной и социопсихологической, так и в информационной медиаcopepe.

Современный арсенал средств манипулирования сверхразнообразен, включает целую гамму специальных приемов, методов и технологий. Вспомним: систематическое внушение социальных мифов, подтасовка фрактов, дифрфамация, распространение мифологем вместо правды, деформированность оценок вместо поощрения к формированию индивидуальных точек зрения, дискретность и фррагментарное комментирование информации с целью представить ее в ущемленном или искаженном виде [15]. Все это приводит к использованию специальных методов формирования так называемого иллюзорного сознания, которое является вторичным продуктом массового сознания как такового.

Чисто технологические методики использования аудиовизуального материала: демонстрация в невыгодном ракурсе по телевидению «неуважаемых» или «опасных» (с точки зрения властного режима) политиков [20; 21]; использование для компрометации противников приемов монтажа кадров; подбор сюжетов, направленных на искажение реальности, и т. д. Так, на примере информационных жанров можно проследить использование общеизвестных коммуникативных приемов манипуляции в сочетании со специальными методами формирования иллюзорного сознания с целью управления, в частности, электоральным поведением масс.

Как вывод следует отметить, что манипулятивность и определенные меры политической направленности никогда не улучшали легитимность власти в сторону ее повышения. Именно это мешает современному состоянию легитимации власти на Украине и ее позиций в политическом спектре. Такие же причины обусловливают и состояние доверия к так называемым правительственным средствам массового информирования, т. е. к тем каналам и программам телевидения и радио или газетам, которые отражают точку зрения высших эшелонов власти. Что касается механизмов формирования массового сознания, то и в условиях кризисного общества они сохраняют свои политико-технологические особенности, которые были им присущи в предыдущие годы. Остаются противоречия между социальными интересами и возможностью их удовлетворить, правом выбора и возмож- 
ностью этого выбора и др. Преодоление кризисных явлений кроется не только в улучшении ситуации в экономике, но и во многом в общественном социопсихологическом климате, необходимости постепенной стабилизации ситуации и восстановлении реальных (а не «ирреальных» или «гиперреальных») отношений внутри страны и вокруг нее. В этих условиях именно массовая коммуникация (а не информирование), основанная на принципах рациогуманизма, может существенно повлиять на позитивное разрешение проблем, восстановить определенный баланс интересов и вернуть хотя бы часть доверия людей к этой сфере.

\section{СПИСОК ИСПОЛЬЗОВАННОЙ ЛИТЕРАТУРЫ}

1. Дридзе Т. М. Социальное управление и социальная коммуникация на рубеже XXI века: к преодолению парадигмального кризиса в социологии / Т. М. Дридзе // В контексте конфликтологии: проблемы коммуникации и управленческого консультирования : в 2 кн. / отв. ред. Т. М. Дридзе, Л. Н. Цой. - М. : Изд-во Ин-та социологии РАН, 1999. Кн. 2. - C. 8-18.

2. Сусская О. А. Методология научного осмысления социальных коммуникаций как регуляторов социальной реальности / О. А. Сусская // Социокультурные среды и коммуникативные стратегии информационного общества : междунар. науч.-теорет. конф., г. Санкт-Петербург, 29-31 окт. 2015 г. - СПб. : Изд-во С.-Петерб. политехн. ун-та им. Петра Великого, 2015. - С. 74-76.

3. Сусская О. А. Информационное пространство и жизненный мир личности / О. А. Сусская // Философия коммуникации: интеллектуальные сети и современные информационно-коммуникативные технологии в образовании / под ред. С. В. Клягина, О. Д. Шипуновой. - СПб. : Изд-во С.-Петерб. политехн. ун-та им. Петра Великого, 2013. - С. 71-82.

4. Балл Г. А. Система принципов рациогуманизма / Г. А. Балл // Психология и общество. - 2011. — № 4. - С. 16-32.

5. Балл Г. А. Личность как модус культуры и как интегративное качество лица / Г. А. Балл, В. А. Мединцев // Мир психологии. - 2010. — № 4. - С. 167-178.

6. Разлогов К. Э. Глобальная или массовая? / К. Э. Разлогов // Общественные науки и современность. - 2003. - № 2. - С. 143-156. $320 \mathrm{c}$.

7. Бодрийяр Ж. Симулякры и симуляция / Ж. Бодрийяр. - М. : Постум, 2017. -

8. Бодалев А. А. Психология массовой коммуникации / А. А. Бодалев. - М. : Гардарики, 2008. - 254 с.

9. Сусская О. А. Культурные проекции пространства медиакоммуникаций / О. А. Сусская // Europaische Fachhochschule. - 2015. - № 6. - С. 52-53.

10. Habermas J. Theorie des kommunikativen Handelns : In 2 Bd. / J. Habermas. Frankfurt am Main, 1981. - Bd. 2 : Zur Kritik der funktionalistischen Vernunft. — $184 \mathrm{~S}$.

11. Балл Г. А. Рациогуманистическая ориентация в методологии человековедения / Г. А. Балл. - М. : СКД, 2017. - 204 с.

12. Laacso M. The «Effective» Number of Parties: A Measure with Applacation to West Europe / M. Laacso, R. Taagepera // Comporative political Studies. - 1979. - Vol. 12, № 1. - P. 3-27.

13. Taagepera R. The Number of Parties as a Function of Heterogeneity and Electoral System / R. Taagepera // Comparative Political Studies. — 1999. — Vol. 32, № 5. — P. 531548.

14. Вишняк А. Изменения основных параметров партийной системы Украины: от выборов 1998 до выборов 2014-го / А. Вишняк // Социология: теория, методы, маркетинг. 2017. — № 2. — С. 167-175. 
15. Цыганов В. В. Лики и обличья гибридного мира. Риски, вызовы, угрозы / В. В. Цыганов. - Киев : Альфа Реклама, 2017. - 120 с.

16. Библер В. С. На гранях логики культуры. Книга избранных очерков / В. С. Библер. - М. : Рус. френоменол. о-во, 1997. - 440 с.

17. Балл Г. А. Психологические принципы современного гуманизма / Г. А. Балл // Вопросы психологии. - 2009. - № 6. - С. 3-12.

18. Иванов В. В. Гуманитарные науки и будущее современной цивилизации / В. В. Иванов // Общественные науки и современность. - 2007. - № 2. - С. 5-12.

19. Bourdieu P. The Field of Cultural Production: Essays on Art and Literature / P. Bourdieu. - London : Polity press, 1993. - 336 p.

20. Эйзенштадт Ш. Н. Революция и преобразование обществ. Сравнительное изучение цивилизаций / Ш. Н. Эйзенштадт. - М. : Аспект-Пресс, 1999. - 415 с.

21. Ekiert G. Time, space and institutional change in Central and Eastern Europe / G. Ekiert, S. Hanson // Capitalism and Democracy in Central and Eastern Europe: Assessing the Legacy of Communist Rule / eds. G. Ekiert, S. Hanson. - Cambridge : Cambridge Univ. Press, 2003. - P. 15-48.

\section{REFERENCES}

1. Dridze T. M. Social management and social communication at the turn of the $21^{\text {st }}$ century: on the issue of overcoming the paradigm crisis in sociology. In Dridze T. M., Tsoi L. N. (eds.). $\checkmark$ kontekste konfliktologii: problemy kommunikatsii i upravlencheskogo konsul'tirovaniya [In the context of conflictology: problems of communication and managerial consulting]. Moscow, Institute of sociology, RAS Publ.,1999, vol. 2, pp. 8-18. (In Russian).

2. Susskaya O. A. Methodology of scientific insight into social communications as regulators of social reality. Sotsiokul'turnye sredy i kommunikativnye strategii informatsionnogo obshchestva. Mezhdunarodnaya nauchno-teoreticheskaya konferentsiya, Sankt-Peterburg, 29-31 oktyabrya $2015 \mathrm{~g}$. [Socio-cultural environment and communication strategies of information society. International academic conference, Saint Petersburg, 29-31 October 2015]. Peter the Great St. Petersburg Polytechnic University Publ., 2015, pp. 74-76. (In Russian).

3. Susskaya O. A. Information space and a person's lifeworld. In Klyagin S. V., Shipunova O. D. (eds.). Filosofiya kommunikatsii: intellektual'nye seti i sovremennye informatsionno-kommunikativnye tekhnologii v obrazovanii [Philosophy of Communication: intellectual networks and modern information-communication technologies in education]. Peter the Great St. Petersburg Polytechnic University Publ., 2013, pp. 71-82. (In Russian).

4. Ball G. A. Principles of ratio-humanism system. Psikhologiya $i$ obshchestvo $=$ Psychology and Society, 2011, no. 4, pp. 16-32. (In Russian).

5. Ball G. A., Medintsev V. A. Personality as a modus of culture and integrative characteristic of a person. Mir psikhologii = World of psychology, 2010, no. 4, pp. 167-178. (In Russian).

6. Razlogov K. E. Global or mass? Obshchestvennye nauki $i$ sovremennost' $=$ Social Science and Modernity, 2003, no. 2, pp. 143-156. (In Russian).

7. Baudrillard J. Simulacres et simulation. Paris, Editions Galilee, 1985. 233 p. (Russ. ed.: Baudrillard J. Simulyakry i simulyatsiya. Moscow, Postum Publ., 2017. 320 p.).

8. Bodalev A. A. Psikhologiya massovoi kommunikatsii [Psychology of mass communication]. Moscow, Gardariki Publ., 2008. 254 p.

9. Susskaya O. A. Cultural projections of media communication space. Europaische Fachhochschule, 2015, no. 6, pp. 52-53. (In Russian).

10. Habermas J. Theorie des kommunikativen Handelns. Frankfurt am Main, 1981. Bd. 2. Zur Kritik der funktionalistischen Vernunft. $184 \mathrm{~S}$.

11. Ball G. A. Ratsiogumanisticheskaya orientatsiya $v$ metodologii chelovekovedeniya [Ratio-humanistic orientation and methodology of humanology]. Moscow, SKD Publ., 2017. $204 \mathrm{p}$.

12. Laacso M., Taagepera R. The «Effective» Number of Parties: A Measure with Applacation to West Europe. Comporative political Studies, 1979, vol. 12, no. 1, pp. 3-27.

13. Taagepera R. The Number of Parties as a Function of Heterogeneity and Electoral System. Comparative Political Studies, 1999, vol. 32, no. 5, pp. 531-548. 
14. Vishnyak A. Changing the main parameters of the Ukrainian party system: from the elections of 1998 until the elections of 2014. Sotsiologiya: teoriya, metody, marketing = Sociology: theory, methods, marketing, 2017, no. 2, pp. 167-175. (In Russian).

15. Tsyganov V. V. Liki i oblich'ya gibridnogo mira. Riski, vyzovy, ugrozy [Faces of the hybrid world. Risks, challenges, threats]. Kiev, Al'fa Reklama Publ., 2017. 120 p.

16. Bibler V. S. Na granyakh logiki kul'tury. Kniga izbrannykh ocherkov [On the cusp of logic of culture. Book of selected essays]. Moscow, Russian Phenomenological Society Publ., 1997. 440 p.

17. Ball G. A. Psychological principles of modern humanism. Voprosy psikhologii $=$ Psychology Questions, 2009, no. 6, pp. 3-12. (In Russian).

18. Ivanov V. V. Humanities and the future of modern civilization. Obshchestvennye nauki i sovremennost' $=$ Social Science and Modernity, 2007, no. 2, pp. 5-12. (In Russian).

19. Bourdieu P. The Field of Cultural Production: Essays on Art and Literature. London, Polity press, 1993. $336 \mathrm{p}$.

20. Eisenstadt S. N. Revolution and the transformation of societies: a comparative study of civilizations. New York, Free Press, 1978. 348 p. (Russ. ed.: Eisenstadt S. N. Revolyutsiya $i$ preobrazovanie obshchestv. Sravnitel'noe izuchenie tsivilizatsii. Moscow, Aspekt-Press Publ., 1999. 415 p.).

21. Ekiert G., Hanson S. Time, space and institutional change in Central and Eastern Europe. In Ekiert G., Hanson S. (eds.). Capitalism and Democracy in Central and Eastern Europe: Assessing the Legacy of Communist Rule. Cambridge, Cambridge University Press, 2003, pp. 15-48.

\section{ДЛЯ ЦИТИРОВАНИЯ}

Сусская О. А. Рациогуманистические тенденции в изучении информационного пространства / О. А. Сусская // Вопросы теории и практики журналистики. - 2018. T. 7, № 2. — C. 266-278. — DOI: 10.17150/2308-6203.2018.7(2).266-278.

\section{FOR CITATION}

Susskaya O. A. Ratio-Humanist Trends in Studying Information Space. Voprosy teorii i praktiki zhurnalistiki = Theoretical and Practical Issues of Journalism, 2018, vol. 7, no. 2, pp. 266-278. DOI: 10.17150/2308-6203.2018.7(2).266-278. (In Russian). 